\title{
Evaluation of HBs-Ag and anti-HBc levels in serum and saliva of patients with hepatitis B
}

\author{
Matine Gharavi ${ }^{1}$ (D) Mostafa Esmaeili ${ }^{1}$ \\ Received: 5 Apr 2019 \\ Published: 19 Aug 2020
}

\section{Abstract}

Background: Hepatitis B is a common infectious disease with serious complications. Health care workers (HCWs) are among the susceptible groups for Hepatitis B Virus (HBV) infection. Hepatitis B Virus is usually diagnosed through serological tests, which are invasive and expensive. Having in mind that saliva can be seen in many cases as an indicator of serological changes, in this study we aimed to assess the specificity and sensitivity of salivary HBs-Ag and anti-HBc, as the 2 diagnostic markers of HBV infection, compared to serological results of these markers.

Methods: Samples were obtained from 39 individuals diagnosed with hepatitis B and 20 healthy individuals. In this study serum HBs$\mathrm{Ag}$ and anti-HBc of all the patients were evaluated by their physicians in the previous week. Unstimulated whole saliva was collected and sent to laboratory for evaluating salivary HBs-Ag and anti-HBc. Specificity and sensitivity were evaluated through data analysis by SPSS software.

Results: Serum was considered as a reference test and saliva as an index test. Sensitivity and specificity for oral fluid assay were measured: Sensitivity and specificity of salivary HBs-Ag were $86 \%$ and $95 \%$, respectively, and they were $71 \%$ and $95 \%$, respectively, for anti-HBc.

Conclusion: Our results suggest that salivary tests of $\mathrm{HBs}-\mathrm{Ag}$ and anti-HBc marker could have the potential to replace serological tests for these markers.

Keywords: Hepatitis B, Saliva, Serum, HBs-Ag, Anti-HBc

Conflicts of Interest: None declared

Funding: None

\section{*This work has been published under CC BY-NC-SA 1.0 license.}

Copyright $\odot$ Iran University of Medical Sciences

Cite this article as: Gharavi M, Esmaeili M. Evaluation of HBs-Ag and anti-HBc levels in serum and saliva of patients with hepatitis B. Med J Islam Repub Iran. 2020 (19 Aug);34:101. https://doi.org/10.47176/mjiri.34.101

\section{Introduction}

Viral Hepatitis B is a significant worldwide health care problem $(1,2)$. HBV is a compact, enveloped virus with a

\section{Corresponding author: Gharavi Matine, Ivlatine@gmail.com}

1. Department of Oral Medicine, Faculty of Dentistry, Shahed University, Tehran, Iran partially double-stranded DNA genome. It is the prototype member of the hepadnaviridae family $(3,4)$. The World

\section{$\uparrow$ What is "already known" in this topic:}

There are several reports of sensitivity and specificity of salivary HBs-Ag and anti-HBc in different studies, but the reports are highly contradictory. Most of these studies did not clarify the exact method of salivary collection or did not collect unstimulated whole saliva, which is the universal standard for HBV diagnosis.

\section{$\rightarrow$ What this article adds:}

This article is a report of both salivary HBs-Ag and anti-HBc. We collected unstimulated whole saliva and included both healthy individuals and hepatitis B patients in the study to make the statistical analysis reliable. Our findings have shown $86 \%$ sensitivity and $95 \%$ specificity for salivary $\mathrm{HBs}-\mathrm{Ag}$ and $71 \%$ sensitivity and $95 \%$ specificity for anti-HBc. Therefore, our results suggest that salivary tests of $\mathrm{HBs}-\mathrm{Ag}$ and anti-HBc marker could have the potential to replace serological tests for these markers. 
Health Organization has approximated there are roughly more than 2 billion people infected with Hepatitis B Virus, with around 378 million chronic carriers worldwide and about 80 million HBV carriers in the Southeast Asia region $(5,6)$. More than $50 \%$ of liver cancer is hepatitis B related $(7,8)$. Viral antigens and antibodies are detected by conventional serological tests. Detecting the Hepatitis B surface antigen (HBs-Ag) indicates the patient is infectious, while the detection of Hepatitis B surface antibody (anti$\mathrm{HBs}$ ) is mainly interpreted as an indicator of recovery and immunity from hepatitis B virus infection. Complete hepatitis B core antibody (anti-HBc) appears at the early stages of acute hepatitis $B$ and persists for life, while the presence of anti-HBc denotes previous or ongoing hepatitis B Virus infection during an undefined time frame $(9,10)$. The relative inconvenience of obtaining blood samples and the risk of blood-borne pathogens make serologic testing unappealing. Many serological antigens and antibodies are detected in salivary secretions; therefore, the usage of oral fluid as an alternative has been extensively studied. The major advantage of oral fluid is the relative ease and speed by which it can be obtained compared to blood and can be self-collected. The collecting is painless and there is no risk for transmission of blood-borne pathogens. Patients can collect the samples at home in their own time $(11,12)$. Therefore, the aim of this study was to evaluate $\mathrm{HBs}-\mathrm{Ag}$ and anti-HBc in saliva of patients with hepatitis B and to compare specificity and sensitivity of salivary $\mathrm{HBs}-\mathrm{Ag}$ and anti-HBc to the same serological markers.

\section{Methods}

A total of 59 individuals, 30 females (51\%) and 29 males (49\%), were sampled for this study; of whom 39 were diagnosed with hepatitis B and 20 were healthy. The patients with hepatitis B Virus infection were referred to Gastrointestinal and Liver Ward of Taleghani Hospital, Tehran, Iran, and evaluated by the physicians with regards to their serological levels of HBs-Ag and anti-HBc in the previous 2 weeks and were included in the study. Consent for participating in the study was obtained from each participant. Ethical committee approval (IR.SHAHED.REC. 1397.015) was also obtained. Serum level assessment of the markers were sought by physicians as a routine process of treatment. Then, 3cc unstimulated whole saliva was collected from each patient by spitting method. Patients were asked not to drink, eat, perform oral hygiene, smoke or put anything in their mouths for 90 minutes prior to the collection of unstimulated whole saliva. Saliva samples were kept frozen in the laboratory of Taleghani hospital at $-20^{\circ} \mathrm{C}$ until analysis. All of the collected samples were coded regardless of the hepatitis condition to ensure blind testing in the sample analysis procedure performed in laboratory. The Markers of HBs-Ag and anti-HBc were investigated in the salivary samples using Enzyme-Linked Immunosorbent Assay (ELISA). The test results of the markers were analyzed versus serum samples in terms of sensitivity and specificity. Serum was considered as a reference test and statistical analysis was done through SPSS software (Version 24). Also, 20 healthy participants were included in the study by the same procedure for statistical analysis.

\section{Results}

In this study, 59 individuals, 30 females (51\%) and 29 males (49\%), were sampled; of them, 39 were diagnosed with hepatitis B and 20 were healthy. After statistical analysis of HBs-Ag and anti-HBc, specificity and sensitivity of each marker were determined (Table 1). Accuracy values (\%) for HBs-Ag and HBs-Ab and anti-HBc tests among saliva samples were compared to serum samples as reference tests.

The sensitivity and specificity of HBs-Ag were $86 \%$ and $95 \%$, respectively, and the sensitivity and specificity of anti-HBc were $71 \%$ and $95 \%$, respectively (Table 1).

\section{Discussion}

Salivary HBs-Ag showed $86 \%$ sensitivity and $95 \%$ specificity versus serum $\mathrm{HBs}-\mathrm{Ag}$ as a reference test. Sensitivity and specificity of anti-HBc were $71 \%$ and $95 \%$, respectively. Therefore, salivary HBs-Ag and anti-HBc have high sensitivity and specificity for HBV infection diagnosis.

Hutse et al (10) in 2005 evaluated oral fluid as a tool for detecting hepatitis B surface antigen. The study aimed to assess the detection of HBs-Ag in oral fluid compared to serum using commercially available ETI-MAK-4 ELISA kits. The study population included $73 \mathrm{HBs}-\mathrm{Ag}$ negative and 43 HBs-Ag positive. Hutse et al (10) reported sensitivity and specificity of $90.7 \%$ and $100 \%$, respectively, which is completely aligned with our study (86\% sensitivity and $95 \%$ specificity). However, Hutse et al failed to clarify the details of the methods used to collect saliva for the experiment.

O'connell et al (11) in 2001 evaluated oral fluid collection by post for viral antibody testing. A total of 962 households were selected nationally to participate in this study. Households received an initial guide in a letter that outlined the purpose of the study. A follow-up letter contained 6 swabs for oral fluid collection. The results of O'connell (11) study was merely an epidemiologic report of salivary anti-HBc marker that was $0.051 \%$, which is very low and is not aligned with our study. There are several problems with this study, as the patients were not instructed meticu-

Table 1. Sensitivity and specificity of salivary HBs-Ag and anti-HBc compared to the same serological values

\begin{tabular}{lcc}
\hline Index & $\begin{array}{c}\text { Serum HBs-Ag as reference test-salivary } \\
\text { HBs-Ag as index test }\end{array}$ & $\begin{array}{c}\text { Serum anti-HBc as reference test-salivary } \\
\text { anti-HBc as index test }\end{array}$ \\
\hline Sensitivity $(95 \% \mathrm{CI})$ & $0.86(0.72-0.94)$ & $0.71(0.55-0.83)$ \\
Specificity (95\% CI) & $0.95(0.78-0.99)$ & $0.95(0.77-0.99)$ \\
PPV $(95 \% \mathrm{CI})$ & $0.97(0.84-0.99)$ & $0.96(0.82-0.99)$ \\
NPV $(95 \% \mathrm{CI})$ & $0.80(0.62-0.91)$ & $0.64(0.46-0.78)$ \\
LR+ (95\% CI) & $19.2(2.7-129.6)$ & $14.8(2.1-102.1)$ \\
LR- $(95 \% \mathrm{CI})$ & $0.14(0.06-0.32)$ & $0.30(0.18-0.50)$ \\
\hline
\end{tabular}


lously on how to collect samples by themselves, which substantially raises the possibility of erroneous sample collection.

Fisker et al (12) in 2002 assessed salivary Anti-HBc. Specificity and sensitivity of anti-HBc tests on saliva were $100 \%$ and $85.9 \%$, respectively, which is in accordance with our study (95\% specificity, $71 \%$ sensitivity). Fisker et al collected salivary samples and then in case of being positive, serological samples were collected as well. Therefore, the high specificity and sensitivity reported by Fisker et al is not statistically reliable and also the difference could be explained by Fisker et al (12)'s dissimilar technique of saliva collection in comparison with our study.

Ravi and Vidya (13) in 2014 performed a comparative ELISA study and evaluated saliva as a diagnostic tool with potential use for hepatitis B infection. Twenty seropositive patients and 20 seronegative patients with hepatitis $B$ viral infection were considered individually. Upon completion, a sensitivity of $45 \%$ and specificity of $100 \%$ were reported for the diagnosis of hepatitis B infection, which is not aligned with our study due to Ravi's sensitivity report. Ravi et al reported a much lower sensitivity compared to our study, and according to their study salivary HBs-Ag cannot replace serum HBs-Ag. Nevertheless, Ravi and Vidya (13) did not clarify the details on the method of salivary collection.

Amado Leon LA (14) published a review article and studied saliva specimen sampling as a noninvasive method with diagnostic and investigational potential for viral hepatitis A, B, and C. According to Amado Leon LA (14), there are several reports of HAV, HBV, HCV salivary antibodies detection and prevalence, but the reports happen to be very contradictive. Many studies analyzed by Amado Leon LA (14) have reported $80 \%$ sensitivity for anti-HBc and $90 \%$ for HBs-Ag. Cruz et al results are thoroughly aligned with our study but they did not report specificity, which is one of the weak points of their study owing to the fact that the clinical value of a test is only justifiable if it is accompanied by both high sensitivity and specificity; otherwise, tests are not reliable enough to be used clinically.

Nokes et al (15) in 2001 studied oral fluid potentiality to replace serum for the assessment of population immunity level. Blood and oral fluid samples were obtained from 853 individuals. Oral fluid assay sensitivity and specificity relative to serum were as follows: $43 \%$ and $87 \%$ for anti-HBc, which are approximately aligned with our study, but they reported lower sensitivity for anti-HBc. However, they did not sufficiently define in their study whether samples were obtained from gingival crevicular fluid (GCF) or unstimulated whole saliva. Furthermore, Nokes et al (15) did not report specificity of Anti-HBc.

\section{Conclusion}

Considering the high specificity and sensitivity of salivary $\mathrm{HBs}-\mathrm{Ag}$ and anti-HBc in our study, we propose these markers be used as a potential substitute for HBV diagnosis.
Conflict of Interests

The authors declare that they have no competing interests.

\section{References}

1. Franco E, Bognato B, Marino MG, Meleleo C, Serino L, Zaratti L. Hepatitis B: Epidemiology \& prevention in developing countries. World J Hepatol. 2012;4(3):74-80.

2. Mahboobi N, Porter SR, Karayiannis P, Alavian SM. Oral fluid and Hepatitis A, B and C: A literature review. J. Oral Pathol. Med. 2011;41(7):505-516.

3. Block TM, Guo H, Guo JT. Molecular virology hepatitis B virus for clinicians. Clin Liver Dis. 2007;11(4):685-706.

4. Liang Jake. Hepatitis B: The Virus and Disease. Hepatology. 2009;49(5):13-21.

5. Khadse SV, Bajaj G, Vibhakar P, Nainani P, Ahuja R, Deep G. Evaluation of specificity and sensitivity of Oral Fluid for Diagnosis of Hepatitis B. J Clin Diagnostic Res. 2016;10(1):12-14.

6. Setia S, Gambhir RS, Kapoor V. Hepatitis B and C infection: Clinical implications in dental practice. Eur J Gen Dent. 2013;2(1):13-19.

7. Philbin MM, Erby LA, Lee S, Juon HS. Hepatitis B and Liver Cancer Among Three Asian American Sub-Groups: A Focus Group Inquiry. J Immigr Minor Health. 2012;14(5):858-868

8. Aljarbou AN. The Emergent Concern of Hepatitis B globally with special attention to Kingdom of Saudi Arabia. Int J Health Sci. 2013;7(3):333-340.

9. Amado LA, Villar LM, De Paula VS, De Almedia AJ, Gaspar AM Detection of hepatitis A, B, and C virus-specific antibodies using oral fluid for epidemiological studies. Mem Inst Oswaldo Cruz. 2006;101(2):149-155.

10. Hutse V, Verhaegen E, De Cock L, Quoilin S, Vandenberghe H, Horsmans $\mathrm{Y}$, et al. Oral fluid as a Medium for the Detection Hepatitis B Surface Antigen. J Med Virol. 2005;77(1):53-56.

11. O'Connell T, Thornton L, O'Flanagan D, Staines A, Connell J, Dooley S, et al. Oral fluid collection by post for viral antibody testing Int J Epidemiol. 2001;30(2):298-301.

12. Fisker N, Georgsen J, Stolborg T, Khalil MR, Christensen PB. Low Hepatitis B Prevalence Among Pre-School Children in Denmark: Saliva Anti-HBc Screening in Day Care Centers. J Med Virol. 2002;68(4):500-504.

13. Ravi BS, Vidya GS. Saliva as a Diagnostic Tool for Hepatitis B Infection- A Comparative ELISA Study. Int $J$ Sci Res Pub. 2014;4(3):2250-3153.

14. Amado Leon LA. Saliva specimen sampling: a noninvasive method for diagnosis and basic investigation of viral hepatitis A, B and C. Future Virol. 2013;8(6):576-588.

15. Nokes DJ, Enquselassie F, Nigatu W, Vyse AJ, Cohen BJ, Brown DW, et al. Has oral fluid the potential o replace serum for the evaluation of population immunity levels? A study of measles, rubella and hepatitis B in rural Ethiopia. Bullet World Health Organ. 2001;79(7):588-595. 